\title{
P-T formation conditions of pegmatites associated with the Taishanmiao granitic batholith, Henan Province, China: Constraints from melt and fluid inclusions
}

\author{
YABIN YUAN $^{1,2}$, ROBERT J. BODNAR ${ }^{2}$
}

${ }^{1}$ MLR Key Laboratory of Metallogeny and Mineral Assessment, Chinese Academy of Geological Sciences, Beijing 100037, China (*correspondence:yabiny@vt.edu) ${ }^{2}$ Department of Geosciences, Virginia Tech, Blacksburg, VA 24061

The Taishanmiao batholith in Henan Province, China, is characterized by late-stage pegmatites that represent the final stages of crystallization of the batholith. In this study, fluid (FI) and melt inclusions (MI) in pegmatitic quartz were studied to constrain the P-T conditions of pegmatite formation. MI begin to melt at $\sim 625^{\circ} \mathrm{C}$ when the heating path intersects the volatile-saturated solidus. Total homogenization of smaller MI occurs at $\sim 780^{\circ} \mathrm{C}$, but some larger MI still contain a vapor bubble at this temperature. Both $\mathrm{H}_{2} \mathrm{O}$ and $\mathrm{CO}_{2}$ have been identified in reheated $\mathrm{MI}$, and their estimated concentrations are $\sim 4.1 \mathrm{wt} \%$, and $580-1300 \mathrm{ppm}$, based on analysis of the glass $\left(\mathrm{H}_{2} \mathrm{O}\right)$ and vapor bubble $\left(\mathrm{CO}_{2}\right)$ by Raman spectroscopy. Assuming a trapping temperature of $780^{\circ} \mathrm{C}$ corresponds to a trapping pressure in the range 2.1-3.3 kbar using MagmaSat[1].

In some pegmatite quartz, MI and FI occur in the same assemblage, suggesting that the melt was volatile saturated and that the MI and FI were trapped on the volatile-saturated solidus. As such, the isochore for the aqueous phase must pass through the MI and FI trapping conditions[2]. Based on microthermometric data for the FI, the isochore was estimated using the model of Steele-MacInnis[3] for the $\mathrm{H}_{2} \mathrm{O}-\mathrm{NaCl}-\mathrm{CO}_{2}$ system. The upper limit for the trapping temperature $\left(780^{\circ} \mathrm{C}\right)$ corresponds to a maximum trapping pressure $\sim 3.9 \mathrm{kbar}$. Our results indicate that the Taishanmiao pegmatite began to form at $\leq 780^{\circ} \mathrm{C}$ and 2.1-3.9 kbar. These results are consistent with a pressure of $\leq 5 \mathrm{kbar}$ previously estimated for formation of the Taishanmiao batholith.

[1] Ghiorso et al. (2015), Contrib Mineral Petr 169. [2] Student \& Bodnar (1996), Petrology 4, 291-306. [3] SteeleMacInnis (2018), Chemical Geology 498, 31-44. 